\title{
Dietary Total Antioxidant Capacity and Dietary Polyphenol Intake and Prevalence of Metabolic Syndrome in Polish Adults: A Nationwide Study
}

\author{
Małgorzata Elżbieta Zujko ${ }^{\mathbb{D}}{ }^{1},{ }^{2}$ Anna Waśkiewicz $\mathbb{D}^{\mathrm{D}}{ }^{2}$ Anna Maria Witkowska ${ }^{\mathbb{D}}{ }^{1}$ \\ Danuta Szcześniewska, ${ }^{2}$ Tomasz Zdrojewski, ${ }^{3}$ Krystyna Kozakiewicz, ${ }^{4}$ \\ and Wojciech Drygas ${ }^{2,5}$ \\ ${ }^{1}$ Department of Food Biotechnology, Medical University of Bialystok, Bialystok, Poland \\ ${ }^{2}$ Department of Epidemiology, Cardiovascular Disease Prevention and Health Promotion, Institute of Cardiology, Warsaw, Poland \\ ${ }^{3}$ Department of Prevention and Education and Department of Hypertension and Diabetology, Medical University of Gdansk, \\ Gdansk, Poland \\ ${ }^{4} 3 r d$ Department of Cardiology, Upper Silesian Centre of Cardiology, Medical University of Silesia, Katowice, Poland \\ ${ }^{5}$ Department of Social and Preventive Medicine, Medical University of Lodz, Lodz, Poland
}

Correspondence should be addressed to Małgorzata Elżbieta Zujko; malgorzata.zujko@umb.edu.pl

Received 13 October 2017; Revised 28 January 2018; Accepted 18 February 2018; Published 26 March 2018

Academic Editor: Luis A. Videla

Copyright ( $) 2018$ Małgorzata Elżbieta Zujko et al. This is an open access article distributed under the Creative Commons Attribution License, which permits unrestricted use, distribution, and reproduction in any medium, provided the original work is properly cited.

Specific classes and subclasses of polyphenols have been studied for their potential effects on noncommunicable diseases, but studies on association between dietary polyphenol intake (DPI) and dietary total antioxidant capacity (DTAC) and MetS (metabolic syndrome) are scarce. Therefore, the aim of this study was to determine associations between DTAC and DPI and the prevalence of MetS and its components in the Polish adult population. Subjects (5690) were participants of the Polish National Multicentre Health Examination Survey (WOBASZ II study) performed in 2013-2014. MetS was defined according to the International Diabetes Federation (IDF) and the American Heart Association/National Heart, Lung, and Blood Institute (AHA/NHLBI) criteria. Daily food consumption was assessed by 24-hour dietary recall. DTAC and DPI were evaluated using the data of food consumption and antioxidant potential of foods, measured by FRAP (ferric reducing antioxidant potential) method, and total polyphenol content in foods, measured by Folin-Ciocalteu assay. Logistic regression models were used to assess the relationship between DTAC and DPI and MetS and its components. Crude, age-adjusted, and multivariable-adjusted models were performed. This study demonstrated that in Polish women, high DPI and high DTAC were significantly associated with a reduced odds ratio for the prevalence of MetS components, such as elevated blood pressure and diabetes. In contrast, in men, high DPI and high DTAC did not have the potential to alleviate MetS components.

\section{Introduction}

Metabolic syndrome (MetS) is a clustering of risk factors, such as central obesity, elevated fasting glucose, elevated triglycerides, reduced high-density lipoprotein cholesterol, and elevated blood pressure, that together culminate in the increased risk of diabetes mellitus type 2 (DM2) and cardiovascular disease (CVD). The first formalized definition of MetS was proposed in 1998 by the World Health
Organization (WHO) [1]. Over the past years, various diagnostic criteria have been presented by different organizations. Most recently, these have come from the International Diabetes Federation (IDF) and the American Heart Association/National Heart, Lung, and Blood Institute (AHA/NHLBI) [2].

The prevalence of MetS varies widely across population and depends on several factors, such as age, gender, socioeconomic status, education level, and lifestyle [3-5]. MetS is 
diagnosed in a third of the US population and a quarter of the European population $[6,7]$. A consequence of metabolic syndrome is CVD and DM2, which are the leading public health problems with high socioeconomic cost. Currently, the global cost of diabetes is $\$ 825$ billion dollars per year [8], while CVD costs US $\$ 555$ billion per year [9] and $€ 210$ billion per year [10].

Several studies have reported that oxidative stress, caused by the imbalance between prooxidants and antioxidants in the living organism system, plays an important role in the prevalence of MetS $[11,12]$. The overproduction of reactive oxygen species may impair insulin signalling pathways and lead to endothelial damage. This causes insulin resistance and promotes acceleration of the atherogenic process [13]. Moreover, oxidative stress and endothelial dysfunction are known to be associated with inflammation and can contribute to hypertension [14].

Modification of lifestyle, including healthy nutrition, is the primary approach for MetS prevention [15]. It was found that the dietary total antioxidant capacity (DTAC), which may increase after dietary polyphenol intake (DPI), has a significant influence on the serum total antioxidant status [16]. Some studies indicated that higher consumption of specific classes of polyphenols $[17,18]$ and DPI [18] and higher DTAC [19-21] have favourable effects on metabolic disorders in different population. Predominant sources of the dietary polyphenols in Polish population are tea, coffee, and apples [22, 23].

The objective of this study was to determine the associations between DTAC and DPI and the prevalence of MetS and its specific components in Polish adult population. To our knowledge, this is the first attempt to estimate the relationships between DTAC and MetS in a cross-sectional Polish study.

\section{Material and Methods}

2.1. Study Population. Subjects were participants of the Polish National Multicentre Health Examination Survey (WOBASZ II study) performed in 2013-2014, which was a crosssectional study aimed at investigating the determinants of chronic noncommunicable diseases in a random sample of Polish residents aged 20 years or older. The project was conducted by the Institute of Cardiology in Warsaw in cooperation with 5 medical universities in Poland. The randomization had two stages. In each of 16 voivodeships, 6 communities were drawn, including 2 small (up to 8000 inhabitants), 2 medium (8000-40000 inhabitants), and 2 large (over 40000 inhabitants) ones, plus province capitals (unless it was selected as one of the communes). Thereafter, 70 men and 70 women were drawn from each community. Altogether, 15120 subjects (including 1557 respondents who were unavailable) of both genders were drawn from the Department of State Registry database, the Ministry of Internal Affairs (PESEL register). A total of 6170 respondents participated in the study, which was $45.5 \%$ of the total sample. Whereas, dietary recalls were obtained from 5690 people (2554 men and 3136 women). The aims and methods of the WOBASZ II study have been described in detail elsewhere $[24,25]$. The participants provided written informed consent, and the study protocol was approved by the Bioethics Committee of the National Institute of Cardiology (number 1344).

2.2. Demographic and Lifestyle Information. Sociodemographic and lifestyle characteristics such as age, gender, educational level, occupational activity, physical activity, smoking habits, and alcohol intake were collected from selfreported standardized questionnaires. Educational level was classified as under middle (primary, vocational, and partial secondary education), middle (secondary and partial academic education), and high (licentiate or university education). Physical activity at leisure for at least $30 \mathrm{~min}$ a day was assessed as low (once a week or less), middle (2-3 times a week), and high level ( $\geq 4$ times a week). Physical activity assessment was described in detail in a previous substudy [26]. Smoking status was categorised as smoking at least one cigarette a day. Alcohol intakes were calculated as gram pure ethanol a day.

2.3. Clinical Measurements. The measurements of body mass, height, waist circumference, and blood pressure were performed by trained nurses, using standardized procedures. Body weight was measured without footwear and without top garments, to the nearest $0.1 \mathrm{~kg}$. Height was measured in the standing position without footwear, to the nearest $0.5 \mathrm{~cm}$. Waist circumference was measured at the level of the umbilicus, using a measuring tape, to the nearest $0.5 \mathrm{~cm}$. Body mass index (BMI) was calculated as body mass in kilograms divided by squared height in meters. A BMI of $18.5-24.9 \mathrm{~kg} / \mathrm{m}^{2}$ was defined as normal body mass, a BMI of $25.0-29.9 \mathrm{~kg} / \mathrm{m}^{2}$ was classified as overweight, and a BMI of over $30.0 \mathrm{~kg} / \mathrm{m}^{2}$ was determined as obesity. Blood pressure was measured three times on the right arm, in a sitting position, at one-minute intervals, using automatic devices AND UA-631, approved by AAMI (Association for the Advancement of Medical Instrumentation). The average value from the second and the third measurements was used for the analysis.

Determinations of fasting glucose and blood lipids were carried out at a single location, Diagnostyka Central Laboratory at the Institute of Cardiology in Warsaw, which holds a CDC certificate (the Centre for Disease Control, Lipid Standardization Program, Atlanta, USA) and the European certificate RIQAS (Random International Quality Assessment Scheme). Measurements of fasting glucose and blood lipids were performed using enzymatic-colorimetric methods on the analyzer Cobas 6000, manufactured by Roche.

2.4. MetS Criteria. MetS criteria were adopted according to the International Diabetes Federation (IDF) and the American Heart Association/National Heart, Lung, and Blood Institute (AHA/NHLBI) definition [2]. MetS was diagnosed when at least three of five risk factors have been identified: (1) elevated waist circumference (for European population: $\geq 94 \mathrm{~cm}$ for men and $\geq 80 \mathrm{~cm}$ for women); (2) elevated triglycerides $(\geq 150 \mathrm{mg} / \mathrm{dl}-1.7 \mathrm{mmol} / \mathrm{l})$; (3) reduced HDL cholesterol $(<40 \mathrm{mg} / \mathrm{dl}-1.0 \mathrm{mmol} / \mathrm{l}$ for men and $<50-$ 
$1.3 \mathrm{mmol} / \mathrm{l}$ for women); (4) elevated blood pressure (systolic $\geq 130$ and/or diastolic $\geq 85 \mathrm{mmHg}$ ) or hypertension in interview; and (5) elevated fasting glucose ( $\geq 100 \mathrm{mg} / \mathrm{dl}-$ $5.6 \mathrm{mmol} / \mathrm{l}$ ) or diabetes in interview.

2.5. Dietary Assessment. Dietary assessment was performed by qualified interviewers, using a single 24-hour dietary recalls. Food portion sizes were estimated using an album with photographs of the most consumed food products established by the National Food and Nutrition Institute, Warsaw, Poland. It was found that 367 of the variety of foods were sources of polyphenol intakes among the whole population of study. These products were grouped in 5 food categories, namely, beverages (alcoholic and nonalcoholic), cereals, fruit, vegetables, and other food products (e.g., chocolates, nuts, and seeds). Individual components of complex dishes were extracted using dish recipes obtained from the Polish Food Composition Tables [27].

2.6. Estimation of DTAC and DPI. DTAC and DPI were determined by multiplying the daily consumption of individual food items by antioxidant capacity of foods and polyphenol contents in these food items. Antioxidant potential of foods, measured by FRAP method (ferric reducing antioxidant potential), was mostly taken from Polish databases [28, 29], and some missing values were complemented with another database [30]. Data on the total polyphenol content in foods, measured by Folin-Ciocalteu assay, were obtained from Polish databases [28, 29], as well as the online Phenol-Explorer database [31].

2.7. Statistical Analysis. Statistical analyses were performed using a Statistical Analysis System (SAS) software, version 9.2. 2 (SAS Institute Inc., Cary, NC). Continuous variables were presented as means and standard deviations (SD) and categorical variables as counts and percentages. KruskalWallis test was used for comparison of continuous variables and chi-square test for categorical variables across categories of DPI and DTAC. Logistic regression models were used to assess the relationship between DPI and DTAC and MetS and its components. Crude, age-adjusted, and multivariable-adjusted models were performed. The results were presented as odds ratios (ORs) and 95\% confidence intervals (CIs) of the associations between MetS and its specific components and tertiles (T1-T3) of DPI and DTAC. The level of significance for two-sided tests was considered to be at $p<0.05$.

\section{Results}

Demographic and lifestyle characteristics of the 5690 participants (2554 men and 3136 women), stratified by occurrence of MetS, are given in Table 1 . The mean age of the studied population was $50.08 \pm 16.44 \mathrm{y}$, and the mean BMI was $27.17 \pm 5.19 \mathrm{~kg} / \mathrm{m}^{2}$. It was found that MetS criteria have been met by $36 \%$ of participants (39\% men and 33\% women). Subjects of older age, higher BMI, low education level, low leisure time physical activity, lack of employment, and high alcohol intake were more likely to have MetS.
Anthropometric characteristics and biomarkers of metabolic syndrome by tertiles of DPI and DTAC are presented in Tables 2 and 3, respectively. Higher DPI and higher DTAC were significantly associated with lower fasting glucose and lower blood pressure, but only in women. There was no significant association in men.

The odds ratios for MetS and its specific components by tertiles of DPI and DTAC were evaluated individually for men and women, using multiple logistic regression analysis (Tables 4 and 5, resp.). Three models were tested: model 1-crude data, model 2-data adjusted for age, and model 3 -data adjusted for age, BMI, educational level, leisure time physical activity, smoking, and alcohol intake. The first tertile (T1) in each model was adopted as a reference. For both genders, the associations between DPI and MetS as well as between DTAC and MetS were not significant after adjustment for multiple covariates (model 3). In men, higher DPI and higher DTAC were associated with reduced odds of diabetes between T3 and T1 $(\mathrm{OR}=0.673,95 \% \mathrm{CI}=0.495-$ 0.917 and $\mathrm{OR}=0.684,95 \% \mathrm{CI}=0.506-0.925$, resp.), but only when the crude data were taken into consideration (model 1). In a single model (model 2) and in a multiple adjustment model (model 3), associations were not statistically significant. Ambiguous results were found for DPI and HDL-cholesterol. In men, higher DPI was significantly associated with lower HDL cholesterol (T3 versus T1; model 3; $\mathrm{OR}=1.410$, 95\% $\mathrm{CI}=1.080-1.842)$; such association was not found for women.

In women, individuals with higher DPI had lower blood pressure (Table 4 ). When the analysis was stratified by multiple covariates (model 3 ), the odds of elevated blood pressure were $22.3 \%$ lower in $\mathrm{T} 2(\mathrm{OR}=0.777,95 \% \mathrm{CI}=0.620-0.975)$ and $30.6 \%$ lower in $\mathrm{T} 3(\mathrm{OR}=0.694,95 \% \mathrm{CI}=0.556-0.867)$ in comparison to T1. Higher DTAC was associated with 22.8\% lower odds of elevated blood pressure between T3 and $\mathrm{T} 1$ in model $3(\mathrm{OR}=0.772,95 \% \mathrm{CI}=0.619-0.963)$ (Table 5). In addition, higher DPI and DTAC in women were significantly associated with reduced odds of elevated blood glucose $(\mathrm{FG} \geq 100 \mathrm{mg} / \mathrm{dl}(5.6 \mathrm{mmol} / \mathrm{dl})$ or diabetes in interview), but only in model 1 . After adjustment for confounding factors (model 3), significant associations were found only for diabetes (FG $\geq 126 \mathrm{mg} / \mathrm{dl}(7 \mathrm{mmol} / \mathrm{l})$ or diabetes in interview) between T2 and T1. In women, higher DPI was associated with $28.2 \%$ lower odds of diabetes ( $\mathrm{OR}=0.718,95 \%$ $\mathrm{CI}=0.520-0.992)$, whereas higher DTAC was associated with $27.9 \%$ lower odds of diabetes $(\mathrm{OR}=0.721,95 \% \mathrm{CI}=$ 0.522-0.997).

\section{Discussion}

In the present study, we evaluated the relationship between DPI and DTAC and MetS and its specific components in Polish representative population of both genders. Inverse associations were evident in women between high DPI, high DTAC, and MetS components, such as elevated blood pressure and diabetes (in a middle tertile). In contrast, in men, high DPI and high DTAC did not have the potential to alleviate MetS components. Moreover, men who consumed more polyphenol had lower HDL-cholesterol. These 
TABLE 1: General characteristics of studied population $(N=5690)$ according to prevalence of metabolic syndrome.

\begin{tabular}{|c|c|c|c|c|}
\hline & \multirow{2}{*}{ Total } & \multicolumn{2}{|c|}{ Metabolic syndrome } & \multirow[b]{2}{*}{$p$} \\
\hline & & No & Yes & \\
\hline Gender, $N(\%)$ & $5690(100)$ & $3662(64.36)$ & $2028(35.64)$ & \\
\hline Men & $2554(44.89)$ & $1554(60.85)$ & $1000(39.15)$ & $<0.0001$ \\
\hline Women & $3136(55.11)$ & $2108(67.22)$ & $1028(32.78)$ & \\
\hline Age (years), mean \pm SD & $50.08 \pm 16.44$ & $46.11 \pm 16.32$ & $57.25 \pm 14.04$ & $<0.0001$ \\
\hline \multicolumn{5}{|l|}{ Age, $N(\%)$} \\
\hline $20-39$ & $1724(30.30)$ & $1485(86.14)$ & $239(13.86)$ & \multirow{3}{*}{$<0.0001$} \\
\hline $40-59$ & $2202(38.70)$ & $1346(61.13)$ & $856(38.87)$ & \\
\hline$>60$ & $1764(31.00)$ & $831(47.11)$ & $933(52.89)$ & \\
\hline $\mathrm{BMI}\left(\mathrm{kg} / \mathrm{m}^{2}\right)$, mean $\pm \mathrm{SD}$ & $27.17 \pm 5.19$ & $25.44 \pm 4.59$ & $30.24 \pm 4.76$ & $<0.0001$ \\
\hline \multicolumn{5}{|l|}{ BMI, $N(\%)$} \\
\hline$<18.5 \mathrm{~kg} / \mathrm{m}^{2}$ & $91(1.61)$ & $91(100.00)$ & $0(0.00)$ & \multirow{4}{*}{$<0.0001$} \\
\hline $18.5-24.9 \mathrm{~kg} / \mathrm{m}^{2}$ & $1985(34.91)$ & $1758(88.58)$ & $227(11.42)$ & \\
\hline $25-29.9 \mathrm{~kg} / \mathrm{m}^{2}$ & $2120(37.25)$ & $1283(60.53)$ & $837(39.47)$ & \\
\hline$>30 \mathrm{~kg} / \mathrm{m}^{2}$ & $1494(26.23)$ & $505(33.78)$ & $989(66.22)$ & \\
\hline \multicolumn{5}{|l|}{ Educational level, $N(\%)$} \\
\hline Under middle & $2274(39.96)$ & $1235(54.29)$ & $1039(45.71)$ & \multirow{3}{*}{$<0.0001$} \\
\hline Middle & $2140(37.62)$ & $1425(66.60)$ & $715(33.40)$ & \\
\hline High & $1276(22.42)$ & $1002(78.49)$ & $274(21.51)$ & \\
\hline \multicolumn{5}{|l|}{ Leisure time physical activity, $N(\%)$} \\
\hline Low level & $2614(45.94)$ & $1601(61.23)$ & $1013(38.77)$ & \multirow{3}{*}{$<0.0001$} \\
\hline Middle level & $1478(25.98)$ & $1035(70.06)$ & $443(29.94)$ & \\
\hline High level & $1598(28.08)$ & $1028(64.32)$ & $570(35.68)$ & \\
\hline \multicolumn{5}{|l|}{ Currently working, $N(\%)$} \\
\hline Yes & $2980(52.37)$ & $2127(71.39)$ & $853(28.61)$ & \multirow[t]{2}{*}{$<0.0001$} \\
\hline No & $2710(47.63)$ & $1534(56.59)$ & $1176(43.41)$ & \\
\hline \multicolumn{5}{|l|}{ Currently smoking, $N(\%)$} \\
\hline Yes & $1647(28.95)$ & 1049 (63.69) & $598(36.31)$ & \multirow[t]{2}{*}{0.0575} \\
\hline No & $4043(71.05)$ & $2411(59.64)$ & $1632(40.36)$ & \\
\hline Alcohol intake (g ethanol/day), mean \pm SD & $5.74 \pm 12.25$ & $5.50 \pm 11.80$ & $6.18 \pm 13.01$ & 0.0368 \\
\hline Energy intake (kcal/day), mean \pm SD & $1965.0 \pm 847.9$ & $1975.0 \pm 831.8$ & $1946.9 \pm 876.1$ & 0.0839 \\
\hline $\mathrm{DPI}(\mathrm{mg} /$ day $)$, mean $\pm \mathrm{SD}$ & $2025.0 \pm 892.0$ & $2036.0 \pm 886.5$ & $2005.2 \pm 901.9$ & 0.1251 \\
\hline DTAC (mmol/day), mean \pm SD & $12.31 \pm 7.37$ & $12.34 \pm 6.86$ & $12.27 \pm 8.22$ & 0.2567 \\
\hline
\end{tabular}

N: number; BMI: body mass index; DTAC: dietary total antioxidant capacity; DPI: dietary polyphenol intake.

differences between genders can be explained by different nutrition habits of both genders and different cut-off points set as criteria for HDL-cholesterol.

To date, only a limited number of epidemiological studies evaluated the association between DPI and MetS and its components. Our results regarding this association between higher DPI and lower risk of diabetes and hypertension in women are in accordance with those found in the HAPIEE (Health, Alcohol and Psychosocial factors In Eastern Europe cohort) study [32, 33]. Similarly, an observational cohort analysis of the nondiabetic participants in the PREDIMED (PREvencion con DIeta MEDiterranea) trial showed that higher DPI was associated with a reduced risk of diabetes in elderly persons at high risk of cardiovascular disease [34]. Moreover, another HAPIEE study indicated that high DPI was negatively associated with MetS components, such as waist circumference, blood pressure, HDL-cholesterol, and triglycerides in women and fasting plasma glucose in both genders [18].

Most of the current epidemiological studies have shown that higher consumption of polyphenols have been related to decreased risk of MetS components, such as diabetes $[17,18,32,34-37]$, hypertension $[17,18,33,38-41]$, central obesity $[17,18]$, dyslipidemia $[17,18,42,43]$, and incidence of cardiovascular events [44], although knowledge on this subject is still scarce and the results are inconsistent. Some studies indicate on the positive impact of dietary total polyphenol intake on lower prevalence of MetS and its components $[18,32-34,42]$, while others show these associations only for selected subclasses of polyphenols [17, 35, 37-40]. Our study added to the current knowledge regarding positive results of dietary total polyphenol intake on lower 
TABLE 2: Anthropometric characteristics and biomarkers of metabolic syndrome by tertiles of DPI and by gender, expressed as mean \pm SD $(N=5690)$.

\begin{tabular}{|c|c|c|c|c|c|c|c|c|}
\hline & \multicolumn{3}{|c|}{ Tertile of DPI, men $(N=2554)$} & \multicolumn{5}{|c|}{ Tertile of DPI, women $(N=3136)$} \\
\hline & $\mathrm{T} 1$ & $\mathrm{~T} 2$ & $\mathrm{~T} 3$ & & $\mathrm{~T} 1$ & $\mathrm{~T} 2$ & $\mathrm{~T} 3$ & \\
\hline & $\begin{array}{c}\text { mean } \pm S D \\
\quad \text { range })\end{array}$ & $\begin{array}{c}\text { mean } \pm S D \\
\text { (range) }\end{array}$ & $\begin{array}{c}\text { mean } \pm S D \\
\text { (range) }\end{array}$ & $p$ & $\begin{array}{c}\text { mean } \pm S D \\
\text { (range) }\end{array}$ & $\begin{array}{c}\text { mean } \pm S D \\
(\text { range })\end{array}$ & $\begin{array}{l}\text { mean } \pm S D \\
\text { (range) }\end{array}$ & $p$ \\
\hline & $\begin{array}{l}1153 \pm 323 \\
(174-1599)\end{array}$ & $\begin{array}{c}1969 \pm 211 \\
(1600-2346)\end{array}$ & $\begin{array}{c}3092 \pm 785 \\
(2347-9048)\end{array}$ & & $\begin{array}{c}1152 \pm 313 \mathrm{mg} \\
(140-1587)\end{array}$ & $\begin{array}{c}1904 \pm 186 \mathrm{mg} \\
(1588-2239)\end{array}$ & $\begin{array}{c}2904 \pm 691 \mathrm{mg} \\
(2240-8793)\end{array}$ & \\
\hline BMI $\left(\mathrm{kg} / \mathrm{m}^{2}\right)$ & $27.30 \pm 4.44$ & $27.42 \pm 4.67$ & $27.53 \pm 4.53$ & 0.7198 & $27.18 \pm 5.64$ & $27.00 \pm 5.65$ & $26.71 \pm 5.66$ & 0.0946 \\
\hline $\mathrm{WC}(\mathrm{cm})$ & $97.31 \pm 12.16$ & $97.39 \pm 13.04$ & $97.00 \pm 12.04$ & 0.8493 & $88.34 \pm 13.79$ & $88.48 \pm 14.06$ & $87.18 \pm 13.46$ & 0.0566 \\
\hline TC $(\mathrm{mmol} / \mathrm{l})$ & $5.22 \pm 1.33$ & $5.17 \pm 1.27$ & $5.23 \pm 1.40$ & 0.7300 & $5.18 \pm 1.24$ & $5.17 \pm 1.19$ & $5.23 \pm 1.23$ & 0.3279 \\
\hline LDL-C (mmol/l) & $3.19 \pm 1.03$ & $3.17 \pm 1.04$ & $3.21 \pm 1.04$ & 0.7121 & $3.10 \pm 1.04$ & $3.08 \pm 0.98$ & $3.16 \pm 1.03$ & 0.1525 \\
\hline HDL-C (mmol/l) & $1.33 \pm 0.40$ & $1.32 \pm 0.43$ & $1.33 \pm 0.46$ & 0.6841 & $1.53 \pm 0.42$ & $1.53 \pm 0.41$ & $1.53 \pm 0.43$ & 0.8516 \\
\hline TG $(\mathrm{mmol} / \mathrm{l})$ & $1.80 \pm 1.92$ & $1.74 \pm 1.53$ & $1.76 \pm 2.21$ & 0.4551 & $1.38 \pm 0.81$ & $1.37 \pm 0.81$ & $1.32 \pm 0.75$ & 0.3001 \\
\hline $\mathrm{FG}(\mathrm{mmol} / \mathrm{l})$ & $5.69 \pm 1.59$ & $5.62 \pm 1.31$ & $5.63 \pm 1.85$ & 0.9001 & $5.56 \pm 1.69$ & $5.34 \pm 1.20$ & $5.26 \pm 0.96$ & 0.0006 \\
\hline $\mathrm{SBP}(\mathrm{mmHg})$ & $135.5 \pm 19.1$ & $134.3 \pm 18.0$ & $133.5 \pm 17.4$ & 0.1357 & $130.1 \pm 20.6$ & $127.0 \pm 19.3$ & $125.8 \pm 19.0$ & $<0.0001$ \\
\hline DBP (mmHg) & $81.8 \pm 11.5$ & $81.3 \pm 11.1$ & $81.5 \pm 10.1$ & 0.8439 & $79.9 \pm 10.6$ & $78.7 \pm 10.7$ & $79.0 \pm 10.6$ & 0.0242 \\
\hline
\end{tabular}

BMI: body mass index; WC: waist circumference; TC: total cholesterol; LDL-C: low-density lipoprotein cholesterol; HDL-C: high-density lipoprotein cholesterol; TG: triglycerides; FG: fasting glucose; SBP: systolic blood pressure; DBP: diastolic blood pressure.

TABLE 3: Anthropometric characteristics and biomarkers of metabolic syndrome by tertiles of DTAC and by gender, expressed as mean \pm SD $(N=5690)$.

\begin{tabular}{|c|c|c|c|c|c|c|c|c|}
\hline & \multicolumn{3}{|c|}{ Tertile of DTAC, men $(N=2554)$} & \multicolumn{5}{|c|}{ Tertile of DTAC, women $(N=3136)$} \\
\hline & $\mathrm{T} 1$ & $\mathrm{~T} 2$ & $\mathrm{~T} 3$ & & $\mathrm{~T} 1$ & $\mathrm{~T} 2$ & T3 & \\
\hline & mean $\pm \mathrm{SD}$ & mean $\pm \mathrm{SD}$ & $\underset{(\text { mean } \pm S D}{S}$ & $p$ & mean \pm SD & mean $\pm \mathrm{SD}$ & mean $\pm \mathrm{SD}$ & $p$ \\
\hline & $5.98 \pm 2.02$ & $11.24 \pm 1.42$ & $19.89 \pm 8.00$ & & $6.28 \pm 2.03$ & $11.39 \pm 1.28$ & $19.12 \pm 8.31$ & \\
\hline & $(0.47-8.83)$ & $(8.84-13.84)$ & $(13.84-95.69)$ & & $(0.32-9.18)$ & $(9.19-13.73)$ & $(13.74-191.82)$ & \\
\hline BMI $\left(\mathrm{kg} / \mathrm{m}^{2}\right)$ & $27.29 \pm 4.51$ & $27.43 \pm 4.59$ & $27.53 \pm 4.54$ & 0.6124 & $27.15 \pm 5.71$ & $26.99 \pm 5.77$ & $26.75 \pm 5.48$ & 0.3117 \\
\hline $\mathrm{WC}(\mathrm{cm})$ & $97.41 \pm 12.37$ & $96.92 \pm 12.89$ & $97.37 \pm 11.99$ & 0.4135 & $88.30 \pm 14.09$ & $88.37 \pm 13.96$ & $87.32 \pm 13.26$ & 0.1440 \\
\hline $\mathrm{TC}(\mathrm{mmol} / \mathrm{l})$ & $5.17 \pm 1.34$ & $5.19 \pm 1.29$ & $5.25 \pm 1.38$ & 0.2944 & $5.17 \pm 1.24$ & $5.20 \pm 1.24$ & $5.21 \pm 1.18$ & 0.4813 \\
\hline LDL-C (mmol/l) & $3.14 \pm 1.00$ & $3.18 \pm 1.06$ & $3.25 \pm 1.04$ & 0.2028 & $3.09 \pm 1.04$ & $3.12 \pm 1.01$ & $3.13 \pm 1.01$ & 0.4652 \\
\hline HDL-C (mmol/l) & $1.32 \pm 0.39$ & $1.32 \pm 0.42$ & $1.34 \pm 0.47$ & 0.6955 & $1.52 \pm 0.41$ & $1.54 \pm 0.43$ & $1.54 \pm 0.42$ & 0.5762 \\
\hline $\mathrm{TG}(\mathrm{mmol} / \mathrm{l})$ & $1.81 \pm 1.99$ & $1.80 \pm 2.19$ & $1.68 \pm 1.48$ & 0.5592 & $1.38 \pm 0.87$ & $1.35 \pm 0.73$ & $1.34 \pm 0.76$ & 0.5926 \\
\hline $\mathrm{FG}(\mathrm{mmol} / \mathrm{l})$ & $5.69 \pm 1.50$ & $5.63 \pm 1.81$ & $5.62 \pm 1.47$ & 0.4232 & $5.50 \pm 1.60$ & $5.39 \pm 1.27$ & $5.35 \pm 1.27$ & 0.0080 \\
\hline $\mathrm{SBP}(\mathrm{mmHg})$ & $135.4 \pm 19.0$ & $134.3 \pm 18.5$ & $133.6 \pm 17.0$ & 0.1637 & $129.3 \pm 20.5$ & $127.8 \pm 19.8$ & $125.8 \pm 18.7$ & 0.0008 \\
\hline $\mathrm{DBP}(\mathrm{mmHg})$ & $81.6 \pm 11.5$ & $81.4 \pm 11.1$ & $81.5 \pm 10.2$ & 0.8380 & $79.3 \pm 10.8$ & $79.3 \pm 10.7$ & $79.0 \pm 10.4$ & 0.8367 \\
\hline
\end{tabular}

BMI: body mass index; WC: waist circumference; TC: total cholesterol; LDL-C: low-density lipoprotein cholesterol; HDL-C: high-density lipoprotein cholesterol; TG: triglycerides; FG: fasting glucose; SBP: systolic blood pressure; DBP: diastolic blood pressure.

blood pressure and occurrence of diabetes in Polish women in a cross-sectional study. It should be pointed that polyphenols are characterized by low bioavailability and their maximal plasma concentrations are reached within the first two hours after ingestion and fall to baseline levels within 8-12 hours. Therefore, the protective effects of polyphenols on MetS may be reached through a long-term regular, daily consumption [45].

Polyphenol-rich foods, such as fruits and vegetables, may exert antioxidant activity, which are the sum of the effects of polyphenols and antioxidant vitamins [16]. In our study, after adjustment for confounding factors, DTAC was significantly associated with lower odds of elevated blood pressure and diabetes (in a middle tertile) in women. However, population studies that examine the relationship between the DTAC and MetS and its components are limited. Similarly to our findings, the results of the EPIC (European Prospective Investigation into Cancer and Nutrition) study showed that the DTAC may play an important role in reducing the risk of diabetes in women [46]. Whereas, the longitudinal TLGS (Tehran Lipid and Glucose Study) showed that higher DTAC was positively associated with lower occurrence of MetS, abdominal obesity, and hypertension [19]. Findings of the Hertfordshire Cohort Study suggested that DTAC may have important protective effects on glucose tolerance, especially in older obese women 
TABLe 4: Odds ratios (OR) (95\% CI (confidence interval)) for metabolic syndrome and its specific components by tertiles of DPI and by gender $(N=5690)$.

\begin{tabular}{|c|c|c|c|c|c|c|}
\hline \multirow{3}{*}{ Characteristic } & \multicolumn{3}{|c|}{ Tertile of DPI, men $(N=2554)$} & \multicolumn{3}{|c|}{ Tertile of DPI, women $(N=3136)$} \\
\hline & T1 (ref.) & $\mathrm{T} 2$ & T3 & T1 (ref.) & $\mathrm{T} 2$ & T3 \\
\hline & & $1600-2346$ & $2347-9048$ & $140-1587$ & $1588-2239$ & $2240-8793$ \\
\hline \multicolumn{7}{|l|}{ Metabolic syndrome } \\
\hline Crude OR (95\% CI) & 1 & $0.990(0.815-1.204)$ & $1.074(0.885-1.305)$ & 1 & $0.813(0.678-0.976)$ & $0.820(0.683-0.983)$ \\
\hline Adjusted OR $(95 \% \mathrm{CI})^{1}$ & 1 & $1.024(0.836-1.254)$ & $1.155(0.944-1.412)$ & 1 & $0.910(0.745-1.111)$ & $1.025(0.840-1.250)$ \\
\hline Adjusted OR $(95 \% \mathrm{CI})^{2}$ & 1 & $0.908(0.720-1.144)$ & $1.044(0.830-1.312)$ & 1 & $0.861(0.688-1.078)$ & $0.952(0.761-1.191)$ \\
\hline \multicolumn{7}{|c|}{$\mathrm{WC} \geq 94 \mathrm{~cm}$ (men), $\geq 80 \mathrm{~cm}$ (women) } \\
\hline Crude OR (95\% CI) & 1 & $0.992(0.815-1.208)$ & $1.065(0.875-1.298)$ & 1 & $0.908(0.750-1.098)$ & $0.883(0.730-1.068)$ \\
\hline Adjusted OR $(95 \% \mathrm{CI})^{1}$ & 1 & $1.010(0.822-1.241)$ & $1.113(0.906-1.367)$ & 1 & $0.994(0.806-1.226)$ & $0.987(0.802-1.215)$ \\
\hline Adjusted OR $(95 \% \mathrm{CI})^{2}$ & 1 & $0.981(0.737-1.307)$ & $1.079(0.812-1.432)$ & 1 & $1.033(0.779-1.370)$ & $1.080(0.818-1.426)$ \\
\hline \multicolumn{7}{|l|}{$\mathrm{TG} \geq 150 \mathrm{mg} / \mathrm{dl}(1.7 \mathrm{mmol} / \mathrm{l})$} \\
\hline Crude OR $(95 \% \mathrm{CI})$ & 1 & $0.889(0.725-1.088)$ & $0.939(0.768-1.148)$ & 1 & $0.992(0.805-1.221)$ & $0.867(0.702-1.071)$ \\
\hline Adjusted OR $(95 \% \mathrm{CI})^{1}$ & 1 & $0.890(0.726-1.090)$ & $0.941(0.769-1.150)$ & 1 & $1.055(0.853-1.306)$ & $0.964(0.776-1.197)$ \\
\hline Adjusted OR $(95 \% \mathrm{CI})^{2}$ & 1 & $0.859(0.691-1.066)$ & $0.899(0.726-1.115)$ & 1 & $1.066(0.849-1.338)$ & $0.937(0.743-1.182)$ \\
\hline \multicolumn{7}{|c|}{ Low HDL-C $<40 \mathrm{mg} / \mathrm{dl}(1.0 \mathrm{mmol} / \mathrm{l})(\mathrm{men}),<50 \mathrm{mg} / \mathrm{dl}(1.3 \mathrm{mmol} / \mathrm{l})$ (women) } \\
\hline Crude OR $(95 \% \mathrm{CI})$ & 1 & $1.102(0.851-1.429)$ & $1.425(1.111-1.828)$ & 1 & $0.889(0.734-1.077)$ & $0.926(0.765-1.120)$ \\
\hline Adjusted OR $(95 \% \mathrm{CI})^{1}$ & 1 & $1.106(0.853-1.433)$ & $1.433(1.117-1.840)$ & 1 & $0.921(0.759-1.119)$ & $0.985(0.812-1.195)$ \\
\hline Adjusted OR $(95 \% \mathrm{CI})^{2}$ & 1 & $1.080(0.818-1.426)$ & $1.410(1.080-1.842)$ & 1 & $0.925(0.751-1.140)$ & $0.939(0.762-1.157)$ \\
\hline \multicolumn{7}{|c|}{$\mathrm{SBP} \geq 130 \mathrm{mmHg}$ or $\mathrm{DBP} \geq 85 \mathrm{mmHg}$ or hypertension in interview } \\
\hline Crude OR $(95 \% \mathrm{CI})$ & 1 & $0.904(0.737-1.109)$ & $0.855(0.698-1.047)$ & 1 & $0.743(0.625-0.884)$ & $0.638(0.536-0.759)$ \\
\hline Adjusted OR $(95 \% \mathrm{CI})^{1}$ & 1 & $0.922(0.741-1.146)$ & $0.869(0.701-1.077)$ & 1 & $0.782(0.634-0.965)$ & $0.703(0.572-0.863)$ \\
\hline Adjusted OR $(95 \% \mathrm{CI})^{2}$ & 1 & $0.956(0.759-1.203)$ & $0.887(0.706-1.113)$ & 1 & $0.777(0.620-0.975)$ & $0.694(0.556-0.867)$ \\
\hline \multicolumn{7}{|c|}{$\mathrm{FG} \geq 100 \mathrm{mg} / \mathrm{dl}(5.6 \mathrm{mmol} / \mathrm{dl})$ or diabetes in interview } \\
\hline Crude OR (95\% CI) & 1 & $1.049(0.859-1.281)$ & $1.023(0.838-1.249)$ & 1 & $0.766(0.629-0.934)$ & $0.692(0.566-0.845)$ \\
\hline Adjusted OR $(95 \% \mathrm{CI})^{1}$ & 1 & $1.106(0.894-1.370)$ & $1.125(0.910-1.390)$ & 1 & $0.845(0.681-1.049)$ & $0.854(0.687-1.061)$ \\
\hline Adjusted OR $(95 \% \mathrm{CI})^{2}$ & 1 & $1.048(0.839-1.310)$ & $1.057(0.848-1.319)$ & 1 & $0.821(0.652-1.034)$ & $0.883(0.700-1.130)$ \\
\hline \multicolumn{7}{|c|}{$\mathrm{FG} \geq 126 \mathrm{mg} / \mathrm{dl}(7 \mathrm{mmol} / \mathrm{l})$ or diabetes in interview } \\
\hline Crude OR (95\% CI) & 1 & $0.922(0.691-1.231)$ & $0.673(0.495-0.917)$ & 1 & $0.649(0.488-0.862)$ & $0.534(0.397-0.720)$ \\
\hline Adjusted OR $(95 \% \mathrm{CI})^{1}$ & 1 & $1.023(0.752-1.392)$ & $0.829(0.598-1.150)$ & 1 & $0.752(0.556-1.017)$ & $0.739(0.538-1.014)$ \\
\hline Adjusted OR $(95 \% \mathrm{CI})^{2}$ & 1 & $0.964(0.697-1.333)$ & $0.797(0.566-1.121)$ & 1 & $0.718(0.520-0.992)$ & $0.780(0.558-1.091)$ \\
\hline
\end{tabular}

WC: waist circumference; TG: triglycerides; HDL-C: high-density lipoprotein cholesterol; SBP: systolic blood pressure; DBP: diastolic blood pressure; FG: fasting glucose. ${ }^{1}$ Analysis adjusted for age; ${ }^{2}$ analysis adjusted for age, BMI, educational level, leisure time physical activity, smoking, and alcohol intake.

[47]. A case-control study showed that higher dietary total antioxidant capacity is inversely related to prediabetes morbidity [48].

In our study, the prevalence of MetS was identified in $36 \%$ of Polish adults, with higher prevalence in men than in women. It was found that the prevalence of MetS in Polish population was increased from $25 \%$ to $36 \%$ between $2003-$ 2005 and 2013-2014 [7]. Our findings correspond with the results of the NHANES (National Health and Nutrition Examination Survey) study, which showed the increase of MetS among US adults (from 29\% to 34\% between 19881994 and 1999-2006, with a greater increase of MetS in women) [49]. In our study, MetS was dependent on various factors, such as gender, age, BMI, education level, leisure time physical activity, employment, and alcohol intake, which is in accordance with other studies [3-7].

Our study has some limitations. The participation rate in the WOBASZ II study was rather low (45.5\%), but typical for cross-sectional studies. This problem was discussed in a previous publication [24]. Next, food intakes were estimated with the single 24-hour dietary recall method that does not reflect habitual or long-term food consumption. However, the 24-hour recall is a common method, which is useful to estimate mean food intakes in large groups of participants. Moreover, this study might have underestimated intakes of some polyphenols and the dietary antioxidant potential of some foods, which have been omitted in the dietary interview or were not included in the polyphenol and antioxidant databases. It was previously found that polyphenol intake estimated according to various databases may substantially differ [50]. Finally, polyphenols in foods and dietary antioxidant capacity can interact with other constituents of foods, which may contribute to the association with prevalence of metabolic disorders. Despite such limitations, this study included a large randomly selected sample of Polish adult population, and clinical measurements and 


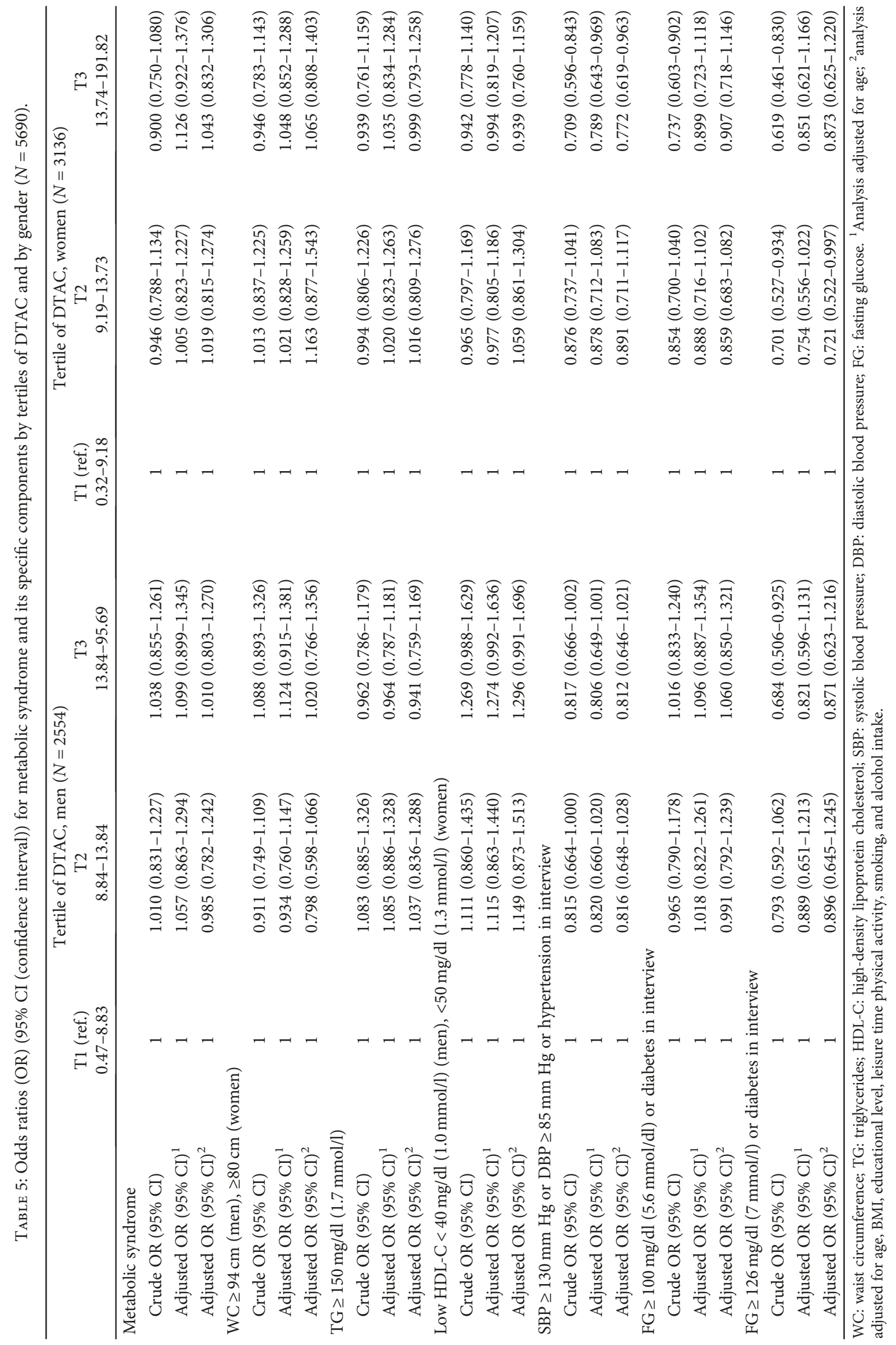


demographic and lifestyle information were based on the standardized procedures.

\section{Conclusion}

This study demonstrated that in Polish women, high DPI and high DTAC were significantly associated with a reduced odds ratio for the prevalence of MetS components, such as elevated blood pressure and diabetes. In contrast, in men, high DPI and high DTAC did not have the potential to alleviate MetS components.

\section{Conflicts of Interest}

The authors declare that there is no conflict of interests regarding the publication of this paper.

\section{Authors' Contributions}

Małgorzata Elżbieta Zujko conceived the idea for the manuscript. Małgorzata Elżbieta Zujko and Anna Waśkiewicz contributed to the study design, analyzed the data, interpreted the results, and wrote the paper. Anna Maria Witkowska contributed to data analysis and interpretation and critically revised the manuscript. Tomasz Zdrojewski, Krystyna Kozakiewicz, and Wojciech Drygas critically revised the manuscript. Anna Waśkiewicz, Danuta Szcześniewska, Tomasz Zdrojewski, Krystyna Kozakiewicz, and Wojciech Drygas provided the data of the WOBASZ II study. Danuta Szcześniewska contributed on data analysis. All authors edited and approved the final version of the manuscript. Małgorzata Elżbieta Zujko and Anna Waśkiewicz contributed equally to this work.

\section{Acknowledgments}

This study was supported by the National Institute of Cardiology (Grant no. 2.17/I/16) and by the Medical University of Bialystok (Grant no. N/ST/ZB/16/003/3317 and Grant no. N/ST/ZB/17/003/3317). The authors express special thanks to the entire research team and collaborators from the field centers in the 16 voivodeships and to all participants of the WOBASZ II study.

\section{References}

[1] K. G. Alberti and P. Z. Zimmet, "Definition, diagnosis and classification of diabetes mellitus and its complications. Part 1: diagnosis and classification of diabetes mellitus. Provisional report of a WHO consultation," Diabetic Medicine, vol. 15, no. 7, pp. 539-553, 1998.

[2] K. G. Alberti, R. H. Eckel, S. M. Grundy et al., "Harmonizing the metabolic syndrome: a joint interim statement of the International Diabetes Federation Task Force on Epidemiology and Prevention; National Heart, Lung, and Blood Institute; American Heart Association; World Heart Federation; International Atherosclerosis Society; and International Association for the Study of Obesity," Circulation, vol. 120, no. 16, pp. 1640-1645, 2009.
[3] A. R. Khang, E. J. Ku, Y. A. Kim et al., "Sex differences in the prevalence of metabolic syndrome and its components in hypopituitary patients: comparison with an age- and sexmatched nationwide control group," Pituitary, vol. 19, no. 6, pp. 573-581, 2016.

[4] M. Novak, L. Björck, L. Welin, C. Welin, K. Manhem, and A. Rosengren, "Gender differences in the prevalence of metabolic syndrome in 50-year-old Swedish men and women with hypertension born in 1953," Journal of Human Hypertension, vol. 27, no. 1, pp. 56-61, 2013.

[5] A. D. Pradhan, "Sex differences in the metabolic syndrome: implications for cardiovascular health in women," Clinical Chemistry, vol. 60, no. 1, pp. 44-52, 2014.

[6] Y. Rochlani, N. V. Pothineni, and J. L. Mehta, "Metabolic syndrome: does it differ between women and men?," Cardiovascular Drugs and Therapy, vol. 29, no. 4, pp. 329-338, 2015.

[7] E. Sygnowska, A. Piwońska, A. Waśkiewicz, and G. Broda, "Socioeconomic factors and the risk of metabolic syndrome in the adult Polish population: the WOBASZ study," Kardiologia Polska, vol. 70, no. 7, pp. 718-727, 2012.

[8] NCD Risk Factor Collaboration (NCD-RisC), "Worldwide trends in diabetes since 1980: a pooled analysis of 751 population-based studies with 4.4 million participants," The Lancet, vol. 387, no. 10027, pp. 1513-1530, 2016.

[9] American Heart Association, "CVD burden report," January 2018, http://www.heart.org/idc/groups/heart-public/@wcm/@ adv/documents/downloadable/ucm_491543.pdf.

[10] The European Heart Network, "European cardiovascular disease statistics 2017," January 2018, http://www.ehnheart.org/ cvd-statistics/cvd-statistics-2017.html.

[11] K. Kotani and N. Taniguchi, "The association between reactive oxygen metabolites and metabolic syndrome in asymptomatic Japanese men," Journal of Clinical Medicine Research, vol. 3, no. 5, pp. 247-251, 2011.

[12] C. K. Roberts and K. K. Sindhu, "Oxidative stress and metabolic syndrome,” Life Sciences, vol. 84, no. 21-22, pp. 705-712, 2009.

[13] K. Maiese, "New insights for oxidative stress and diabetes mellitus," Oxidative Medicine and Cellular Longevity, vol. 2015, Article ID 875961, 17 pages, 2015.

[14] Q. N. Dinh, G. R. Drummond, C. G. Sobey, and S. Chrissobolis, "Roles of inflammation, oxidative stress, and vascular dysfunction in hypertension," BioMed Research International, vol. 2014, Article ID 406960, 11 pages, 2014.

[15] M. F. Piepoli, A. W. Hoes, S. Agewall et al., "2016 European guidelines on cardiovascular disease prevention in clinical practice," European Heart Journal, vol. 37, no. 29, pp. 23152381, 2016.

[16] M. E. Zujko, A. M. Witkowska, M. Górska, J. Wilk, and A. Krętowski, "Reduced intake of dietary antioxidants can impair antioxidant status in type 2 diabetes mellitus patients," Polish Archives of Internal Medicine, vol. 124, no. 11, pp. 599607, 2014.

[17] G. Sohrab, S. Hosseinpour-Niazi, J. Hejazi, E. Yuzbashian, P. Mirmiran, and F. Azizi, "Dietary polyphenols and metabolic syndrome among Iranian adults," International Journal of Food Sciences and Nutrition, vol. 64, no. 6, pp. 661-667, 2013.

[18] G. Grosso, U. Stepaniak, A. Micek, D. Stefler, M. Bobak, and A. Pająk, "Dietary polyphenols are inversely associated with metabolic syndrome in Polish adults of the HAPIEE study," European Journal of Nutrition, vol. 56, no. 4, pp. 14091420, 2017. 
[19] Z. Bahadoran, M. Golzarand, P. Mirmiran, N. Shiva, and F. Azizi, "Dietary total antioxidant capacity and the occurrence of metabolic syndrome and its components after a 3-year follow-up in adults: Tehran Lipid and Glucose Study," Nutrition \& Metabolism, vol. 9, no. 1, pp. 70-79, 2012.

[20] P. Lopez-Legarrea, R. de la Iglesia, I. Abete et al., "Short-term role of the dietary total antioxidant capacity in two hypocaloric regimes on obese with metabolic syndrome symptoms: the RESMENA randomized controlled trial," Nutrition \& Metabolism, vol. 10, no. 1, p. 22, 2013.

[21] B. Puchau, M. A. Zulet, A. G. de Echávarri, H. H. M. Hermsdorff, and J. A. Martínez, "Dietary total antioxidant capacity is negatively associated with some metabolic syndrome features in healthy young adults," Nutrition, vol. 26, no. 5, pp. 534-541, 2010.

[22] M. E. Zujko, A. M. Witkowska, A. Waśkiewicz, W. Piotrowski, and K. M. Terlikowska, "Dietary antioxidant capacity of the patients with cardiovascular disease in a cross-sectional study," Nutrition Journal, vol. 14, no. 1, p. 26, 2015.

[23] M. E. Zujko, A. M. Witkowska, A. Waśkiewicz, and I. Mirończuk-Chodakowska, "Dietary antioxidant and flavonoid intakes are reduced in the elderly," Oxidative Medicine and Cellular Longevity, vol. 2015, Article ID 843173, 8 pages, 2015.

[24] W. Drygas, A. A. Niklas, A. Piwońska et al., "Multi-Centre National Population Health Examination Survey (WOBASZ II study): assumptions, methods, and implementation," Kardiologia Polska, vol. 74, no. 7, pp. 681-690, 2016.

[25] A. Waśkiewicz, D. Szcześniewska, D. Szostak-Węgierek et al., "Are dietary habits of the Polish population consistent with the recommendations for prevention of cardiovascular disease? - WOBASZ II project," Kardiologia Polska, vol. 74, no. 9, pp. 969-977, 2016.

[26] M. Kwaśniewska, M. Pikala, W. Bielecki et al., "Ten-year changes in the prevalence and socio-demographic determinants of physical activity among Polish adults aged 20 to 74 years. Results of the National Multicenter Health Surveys WOBASZ (2003-2005) and WOBASZ II (2013-2014)," PLoS One, vol. 11, no. 6, article e0156766, 2016.

[27] H. Kunachowicz, I. Nadolna, B. Przygoda, and K. Iwanow, Food Composition Tables, Medical Publishing House PZWL, Warsaw, 2005.

[28] M. E. Zujko and A. M. Witkowska, "Antioxidant potential and polyphenol content of selected food," International Journal of Food Properties, vol. 14, no. 2, pp. 300-308, 2011.

[29] M. E. Zujko and A. M. Witkowska, "Antioxidant potential and polyphenol content of beverages, chocolates, nuts and seeds," International Journal of Food Properties, vol. 17, no. 1, pp. 86-92, 2014.

[30] M. H. Carlsen, B. L. Halvorsen, K. Holte et al., "The total antioxidant content of more than 3100 foods, beverages, spices, herbs and supplements used worldwide," Nutrition Journal, vol. 9, no. 1, p. 3, 2010.

[31] V. Neveu, J. Perez-Jiménez, F. Vos et al., "Phenol-Explorer: an online comprehensive database on polyphenol contents in foods," Database, vol. 2010, article bap024, 2010.

[32] G. Grosso, U. Stepaniak, A. Micek et al., "Dietary polyphenol intake and risk of type 2 diabetes in the Polish arm of the health, alcohol and psychosocial factors in Eastern Europe (HAPIEE) study," The British Journal of Nutrition, vol. 118, no. 1, pp. 60-68, 2017.
[33] G. Grosso, U. Stepaniak, A. Micek et al., "Dietary polyphenol intake and risk of hypertension in the Polish arm of the HAPIEE study," European Journal of Nutrition, pp. 1-10, 2017.

[34] PREDIMED study investigators, A. Tresserra-Rimbau, M. Guasch-Ferré et al., "Intake of total polyphenols and some classes of polyphenols is inversely associated with diabetes in elderly people at high cardiovascular disease risk," The Journal of Nutrition, vol. 146, no. 4, pp. 767-777, 2016.

[35] R. Zamora-Ros, N. G. Forouhi, S. J. Sharp et al., "The association between dietary flavonoid and lignan intakes and incident type 2 diabetes in European populations: the EPIC-InterAct study," Diabetes Care, vol. 36, no. 12, pp. 3961-3970, 2013.

[36] Q. Sun, N. M. Wedick, S. S. Tworoger et al., "Urinary excretion of select dietary polyphenol metabolites is associated with a lower risk of type 2 diabetes in proximate but not remote follow-up in a prospective investigation in 2 cohorts of US women," The Journal of Nutrition, vol. 145, no. 6, pp. 12801288, 2015.

[37] N. M. Wedick, A. Pan, A. Cassidy et al., "Dietary flavonoid intakes and risk of type 2 diabetes in US men and women," American Journal of Clinical Nutrition, vol. 95, no. 4, pp. 925-933, 2012.

[38] A. Cassidy, É. J. O'Reilly, C. Kay et al., "Habitual intake of flavonoid subclasses and incident hypertension in adults," The American Journal of Clinical Nutrition, vol. 93, no. 2, pp. 338-347, 2011.

[39] A. Jennings, A. A. Welch, S. J. Fairweather-Tait et al., "Higher anthocyanin intake is associated with lower arterial stiffness and central blood pressure in women," The American Journal of Clinical Nutrition, vol. 96, no. 4, pp. 781-788, 2012.

[40] A. M. Miranda, J. Steluti, R. M. Fisberg, and D. M. Marchioni, "Association between polyphenol intake and hypertension in adults and older adults: a population-based study in Brazil," PLoS One, vol. 11, no. 10, article e0165791, 2016.

[41] S.-H. Li, P. Zhao, H.-B. Tian, L. H. Chen, and L. Q. Cui, "Effect of grape polyphenols on blood pressure: a meta-analysis of randomized controlled trials," PLoS One, vol. 10, no. 9, article e0137665, 2015.

[42] M. Vitale, O. Vaccaro, M. Masulli et al., "Polyphenol intake and cardiovascular risk factors in a population with type 2 diabetes: the TOSCA.IT study," Clinical Nutrition, vol. 36, no. 6, pp. 1686-1692, 2017.

[43] G. Annuzzi, L. Bozzetto, G. Costabile et al., "Diets naturally rich in polyphenols improve fasting and postprandial dyslipidemia and reduce oxidative stress: a randomized controlled trial," The American Journal of Clinical Nutrition, vol. 99, no. 3, pp. 463-471, 2014.

[44] A. Tresserra-Rimbau, E. B. Rimm, A. Medina-Remón et al., "Inverse association between habitual polyphenol intake and incidence of cardiovascular events in the PREDIMED study," Nutrition, Metabolism \& Cardiovascular Diseases, vol. 24, no. 6, pp. 639-647, 2014.

[45] G. Chiva-Blanch and L. Badimon, "Effects of polyphenol intake on metabolic syndrome: current evidences from human trials," Oxidative Medicine and Cellular Longevity, vol. 2017, Article ID 5812401, 18 pages, 2017.

[46] F. R. Mancini, A. Affret, C. Dow et al., "Dietary antioxidant capacity and risk of type 2 diabetes in the large prospective E3N-EPIC cohort," Diabetologia, vol. 61, no. 2, pp. 308 316, 2018. 
[47] H. Okubo, H. E. Syddall, D. I. Phillips et al., "Dietary total antioxidant capacity is related to glucose tolerance in older people: the Hertfordshire Cohort Study," Nutrition, Metabolism \& Cardiovascular Diseases, vol. 24, no. 3, pp. 301-308, 2014.

[48] G. Sotoudeh, M. Abshirini, F. Bagheri, F. Siassi, F. Koohdani, and Z. Aslany, "Higher dietary total antioxidant capacity is inversely related to prediabetes: a case-control study," Nutrition, vol. 46, pp. 20-25, 2018.

[49] A. Mozumdar and G. Liguori, "Persistent increase of prevalence of metabolic syndrome among U.S. adults: NHANES III to NHANES 1999-2006," Diabetes Care, vol. 34, no. 1, pp. 216-219, 2011.

[50] A. M. Witkowska, M. E. Zujko, A. Waśkiewicz, K. Terlikowska, and W. Piotrowski, "Comparison of various databases for estimation of dietary polyphenol intake in the population of Polish adults," Nutrients, vol. 7, no. 11, pp. 9299-9308, 2015. 


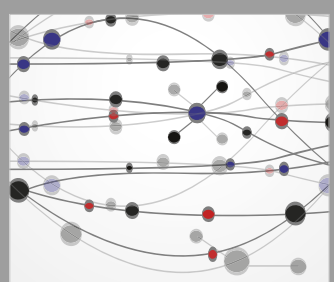

The Scientific World Journal
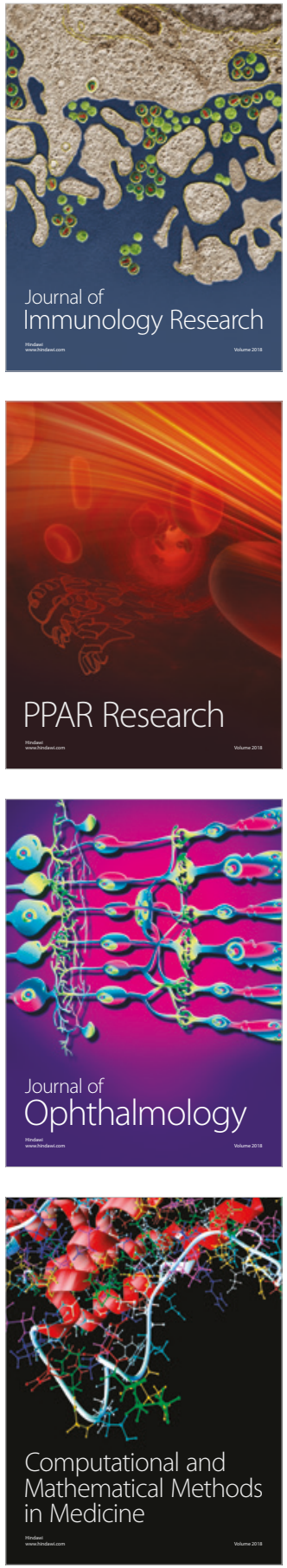

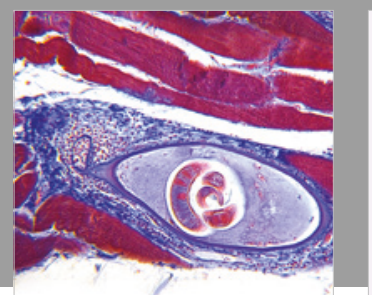

Gastroenterology Research and Practice

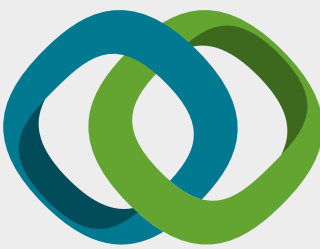

\section{Hindawi}

Submit your manuscripts at

www.hindawi.com
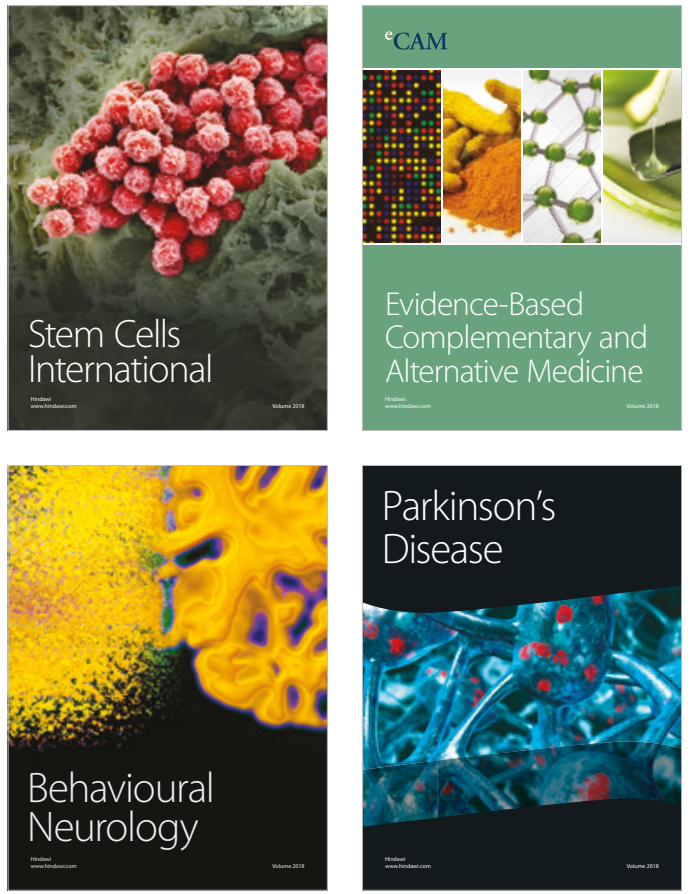

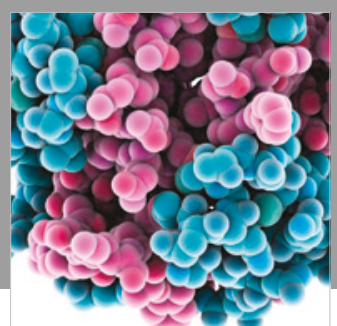

ournal of

Diabetes Research

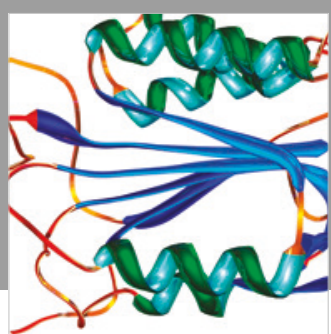

Disease Markers
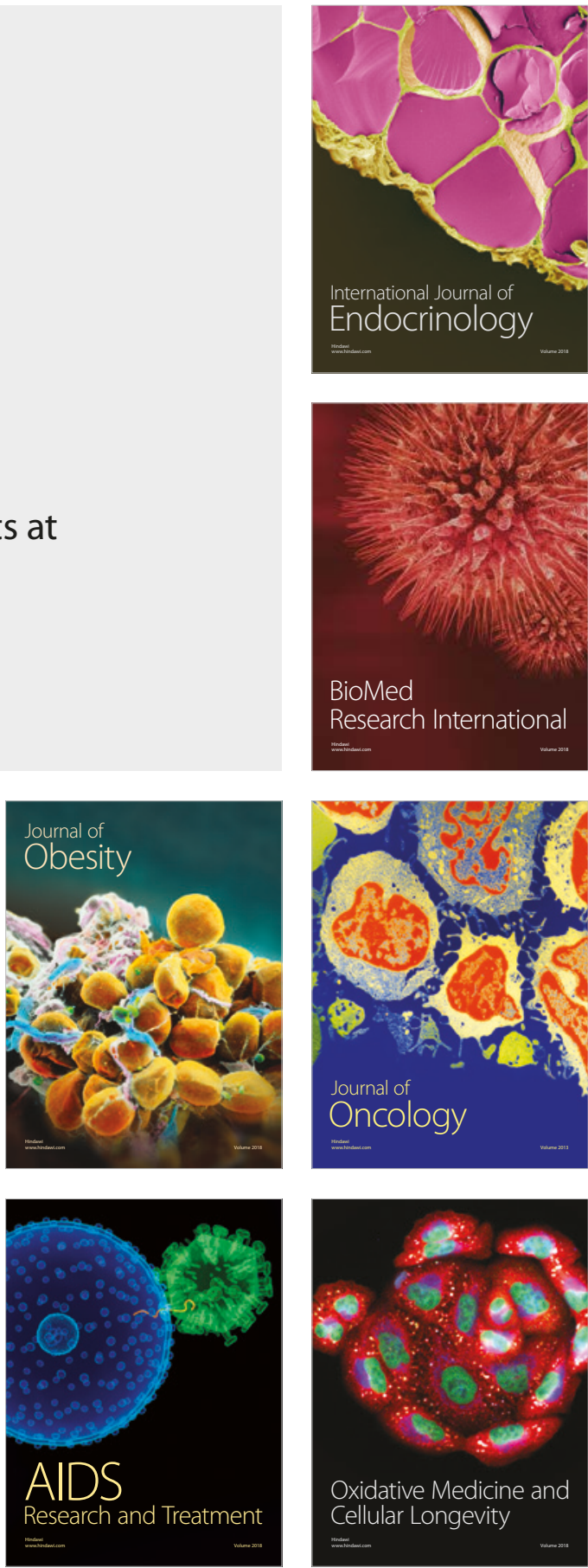